\title{
Low-Cost Data Acquisition Systems for Photovoltaic System Monitoring and Usage Statistics
}

\author{
Sofia Fanourakis ${ }^{1}$, Kevin Wang ${ }^{2}$, Patrick McCarthy ${ }^{1}$ and Lihong (Heidi) Jiao ${ }^{1}$ \\ 1. School of Engineering, Grand Valley State University, Grand Rapids, MI 49504, USA \\ 2. Forest Hills Central High School, Grand Rapids, MI 49546, USA
}

Received: October 25, 2017 / Accepted: November 08, 2017 / Published: November 30, 2017

\begin{abstract}
This paper presents the design of a low-cost DAS (data acquisition system) for monitoring a PV (photovoltaic) system's electrical quantities, battery temperatures, and state of charge of the battery. The electrical quantities are the voltages and currents of the solar panels, the battery, and the system loads. The system uses an Atmega328p microcontroller to acquire data from the PV system's charge controller. It also records individual load information using current sensing resistors along with a voltage amplification circuit and an analog to digital converter. The system is used in conjunction with a wall power DAS for the recording of regional power outages. Both DASs record data in microSD cards. The data have been successfully acquired from both systems and have been used to monitor the status of the PV system and the local power grid. As more data are gathered, it can be used for the maintenance and improvement of the PV system through analysis of the PV system's parameters and usage statistics.
\end{abstract}

Key words: Low-cost, data acquisition, PV system, microcontroller.

\section{Introduction}

As a result of increasing energy demand and gradually shrinking fossil fuel supplies, efforts have been made to explore alternative energy resources. Among these resources, solar energy is the most abundant, clean, and renewable alternative energy source available. Solar PV (photovoltaic) is deemed as a scalable and sustainable solution to the energy shortage problem. PV system performance is largely dependent on the location and conditions of the PV panels. Panel temperature, shading, and dust can affect the system performance; in some regions up to $70 \%$ of power losses could be from panel soiling [1]. Degradation of the panels can also reduce the system performance [2]. Thus, continuous monitoring of PV systems is important in maintaining and improving

Corresponding author: Lihong (Heidi) Jiao, Ph.D., professor, research fields: fabrication and characterization of semiconductor devices including inorganic/organic solar cells; photovoltaic systems; and fiber optic communication systems. their performance.

In recent years, a number of data-logging devices have been developed to monitor PV systems. Commercially available PV monitoring systems capable of monitoring PV system health and usage are costly. For example, systems such as the TED Pro Home Energy Monitor or the Outback Power Flexware FN-DC Flexnet Advanced DC System Monitor can cost more than $\$ 300$. While these components are optional, they are a valuable tool in ensuring the longevity of the PV system as a whole. PV monitoring systems allow for timely replacement of faulty components as well as the replacement of underperforming parts. Thus far, low-cost DASs (data acquisition systems) have been developed in the research setting [2-10]. As many PV systems are located in areas that are difficult to access, some devices have incorporated concepts of low-maintenance and automated data collection into their designs. Ammar Mahjoubi et al. [3] presented a 
low-cost DAS for a remote PV water pumping system. A 10-bit 16F877 microcontroller was used to collect information which was stored in an EEPROM memory and then transferred to a personal computer through the SMS (Short text Message Service) [3]. Mukaro et al. [5] designed a DAS for solar radiation and environmental monitoring. The system was based on the ST62E20 8-bit microcontroller and the SolData silicon-cell pyranometer. The solar radiation information was stored in a serial EEPROM and later transferred to the computer through the RS232 serial port. In the paper presented by Akposionu et al. [6], a low-cost data logger for solar energy parameters was designed and fabricated. The data logger used the Microchip PIC18F4550 microcontroller to monitor the solar panel voltages and the ambient temperature. Purwadi et al. [9] prototyped a low-cost data logger for a PV based LED street lighting system. Their data logger was developed based on Atmel Atmega 8 microcontroller, Dallas DS 1307 RTC (Real Time Clock) and a serial EEPROM from Microchip. Information (the status of PV cell, battery, charge controller, and LED lamp) was saved in the memory and sent to the computer through RS232 serial port.

Many other features were unique to specific data loggers. Chiandone et al. [11] used an Ethernet/TCP-IP communication network to collect and transfer data from PV fields. An IP-enabled data acquisition device was used to successfully transfer data [12]. The data logger developed by Akposionu et al. [6] focused on the accuracy of each measurement, and thus created a data logger capable of collecting and storing data every three seconds. While real-time access to data may be an important feature in some systems, in others it is not as critical; in such cases, local data storage can be used. To this end, SD cards provide an effective storage method and using multiple cards can ensure the data are recorded without corruption [13].

As each device is developed for a different, specific scenario, each contains deficiencies within their designs when employed for a different scenario. The system to be monitored in this paper (the Solar Suction Surgery System, or S4) is located in Malawi. It is used to provide power for lighting, phones, tablets, and a suction machine at the Embangweni Mission hospital. The battery is charged using a solar panel, and power is provided to five auxiliary ports. Due to its remote nature, local resources, and cost considerations, the DAS described in this paper employs microSD cards for its data transfer; this allows for large data sets to be stored as well as the intercontinental transfer of the data. A microcontroller is utilized to acquire PV system parameters such as voltages and currents of the solar panel, the battery, the loads, as well as the ambient and battery temperatures. Furthermore, auxiliary sensors were used for the acquisition of specific usage information.

The data acquisition module detailed within this paper merges many past ideas while also improving on ease of integration. The data logger was designed with low cost as its core concept. Along with this concept, the system takes into account the difficulty of constant physical collection of data. To remedy this issue as well as simplify intercontinental transfer of data, microSD cards were used for data storage. Additionally, the designed data logging system directly accesses the charge controller, so no additional sensors are necessary to acquire parameters from solar panel and battery. Because of this simplification, the data logger can be easily integrated to PV systems and is capable of commercialization and operating in a real world environment. The monitored system is used in a healthcare environment. As such, it is essential to acquire information on the system parameters and usage in order to provide maintenance and future improvements. To this end, the data logger of the S4 is used in conjunction with a data logger monitoring the power outages of the region; the data are compared in order to examine the correlation between system usage (of the S4) and regional power outages. 


\section{Design}

\subsection{Hardware Design}

\subsubsection{S4 Data Logging System}

The main hardware components of the S4 data logging system include an Atmaga328 microcontroller (KOOKYE Mini USB Arduino Nano V3.0 ATMEGA328P), an MAX485 RS485 transceiver, a microSD card reader breakout board, two LEDs, and two buttons. Fig. 1 shows a high level block diagram of the system.

The charge controller records the total load current; thus, additional circuitry was designed to enable the acquisition of the individual load currents. Four current sensing circuits were added at each load. The fifth current is calculated from the difference of the total load current and the sum of the four recorded currents. A differential transimpedance amplifier circuit with a gain of approximately 100 was included for each sensing circuit to convert current to voltage to be recorded by the microcontroller's analog read ports. To store the charge controller data as well as the four load information, a microSD card breakout board was added. Due to the remote nature of the solar unit it was determined that utilizing SD cards for the transfer of data would be the most cost effective method since it requires little maintenance. The file size is small enough to email with a PC or send via a messaging app on a mobile phone. Two LEDs and two pushbuttons were incorporated to allow the user to safely eject the SD card and allow for the communication of errors and system status. Fig. 2 shows the schematic of the S4 data logging system.

\subsubsection{Wall Power Data Logging System}

The wall power data logging system was similar in structure to the S4 data logging system. The main components of the wall power data logger include an Atmega328 microcontroller, an SD card reader breakout board, a RTC, a $4.7 \mathrm{mF}$ capacitor, two LEDs, and two push buttons. Fig. 3 shows a high level block diagram of the system.

The wall power data logger was designed to record a timestamp to the SD card on every boot, and at 5 minute intervals once connected to a power outlet. Power outage data may be gleaned from the timestamps. To protect the system and allow for uncorrupted data to be written to the microSD card, a $4.7 \mathrm{mF}$ capacitor was added. This enabled the stalling of the loss of power, allowing for one last data line to be written to the microSD card. The date and time were determined using an RTC. The RTC was equipped with a rechargeable battery to retain the date and time data regardless of the availability of power. Fig. 4 shows the schematic of the wall power data logging system.

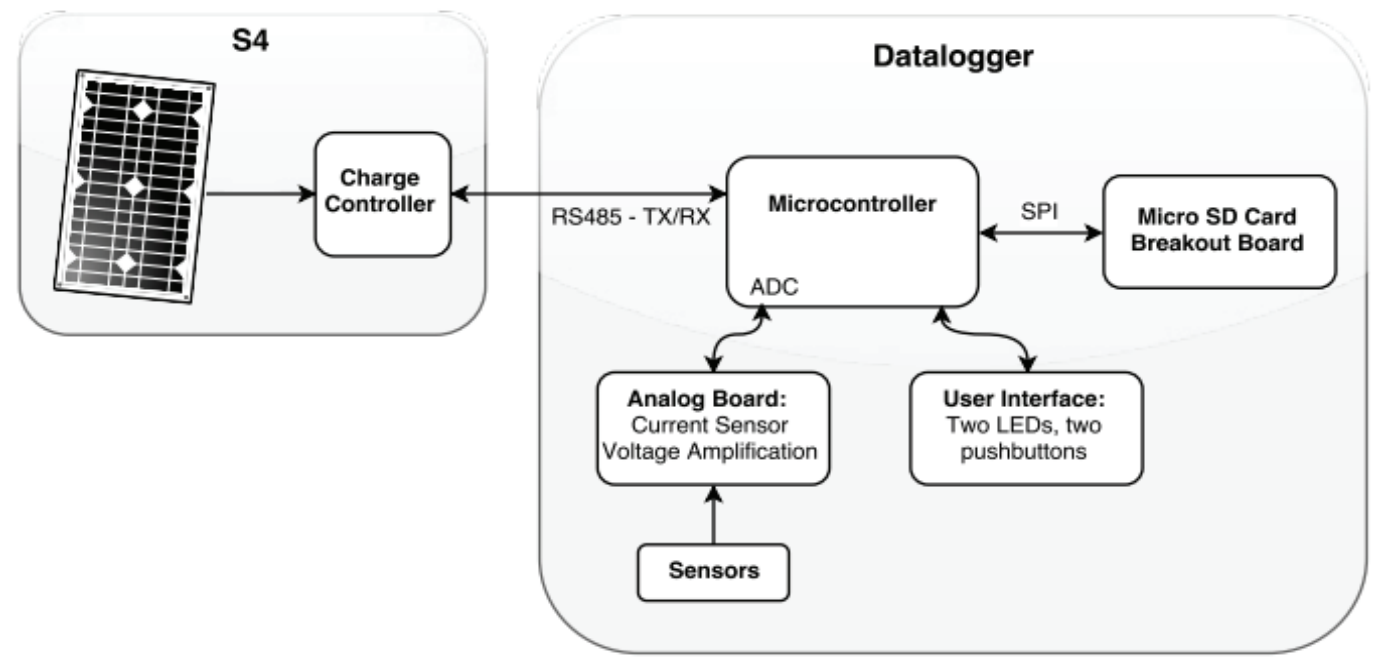

Fig. 1 S4 data logging system block diagram. 


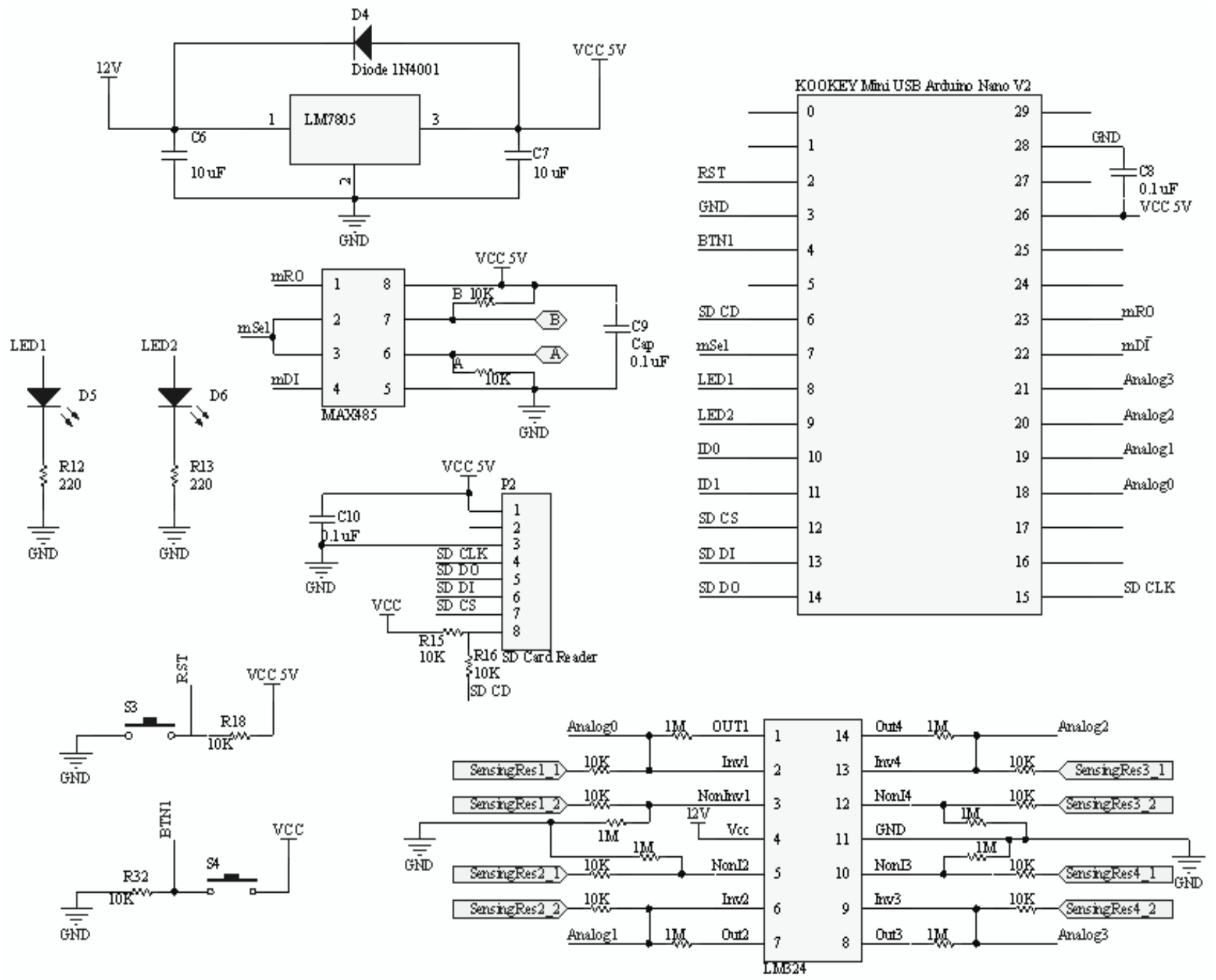

Fig. 2 Schematic of the S4 data logging system.

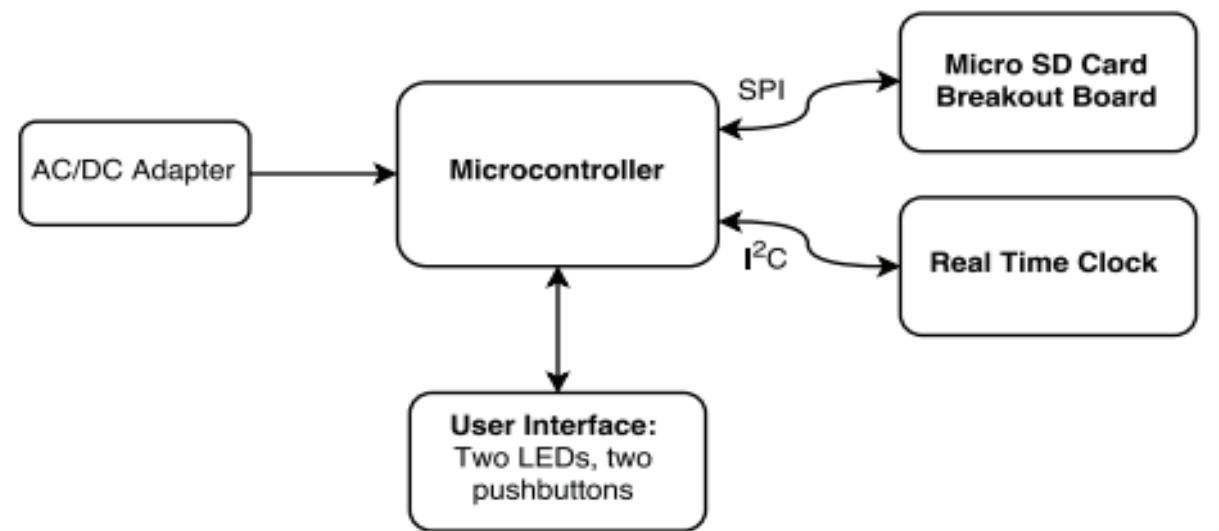

Fig. 3 Wall power data logging system block diagram. 


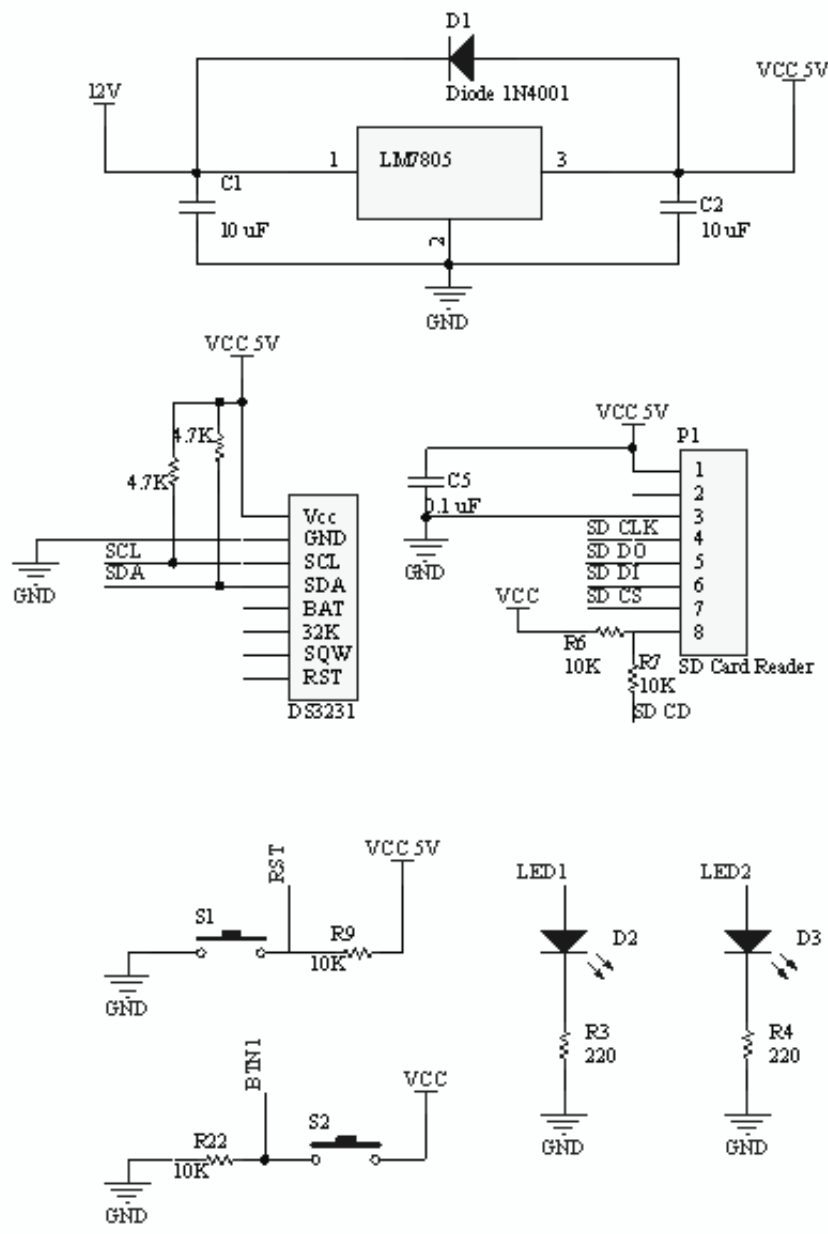

Fig. 4 Schematic of the wall power data logging system.

\subsection{Software Design}

\subsubsection{S4 Data Logging System}

An Atmega328 microcontroller was utilized due to its versatility and readily available libraries enabling serial and SPI communication. The MAX485 transceiver chip was necessary for the microcontroller to communicate with the solar charge controller. Charge controllers such as the Renogy VS1024BN charge controller are equipped with RJ45 ports enabling communication with a computer or an external display. The Modbus RTU protocol is utilized via an RS-485 communication bus interface for communication. The MAX485 chip was selected to enable the RS-485 serial communication. Functions were written with the aid of the serial library in accordance with the Modbus protocol and the charge controller's register information. The microcontroller was programmed to

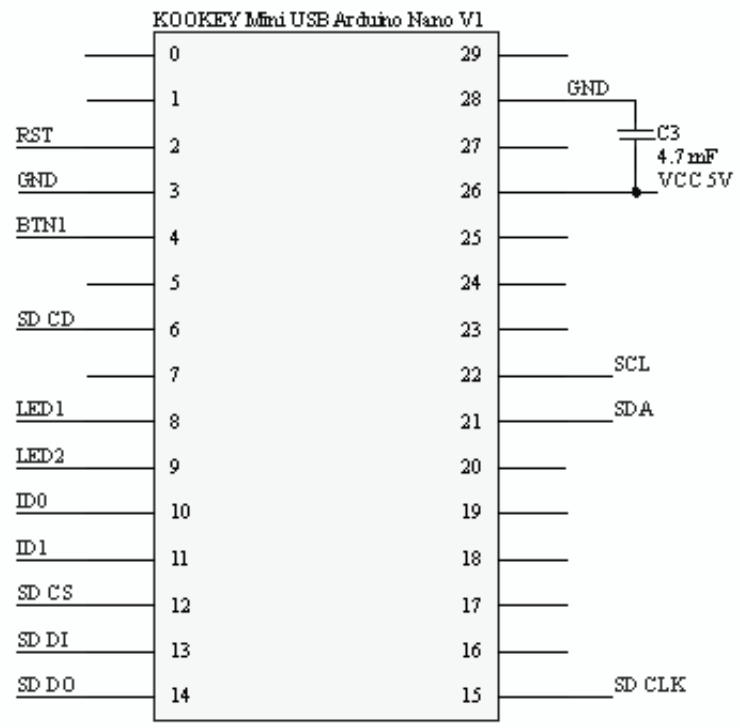

acquire the following information from the charge controller every five minutes: date, time, solar panel voltage, solar panel current, battery voltage, battery current, load voltage, load current, battery state of charge, remote temperature sensor temperature, ambient temperature, and internal temperature. Fig. 5 displays the code flowchart for the S4 data logging unit.

\subsubsection{Wall Power Data Logging System}

The wall power data logging system had a nearly identical software design to the S4 data logging system. However, instead of the microcontroller requesting data from the charge controller, the microcontroller requested data from the real time clock. For this functionality, the $\mathrm{I}^{2} \mathrm{C}$ communication was enabled and functions were written to request and receive date and time data from the RTC. 


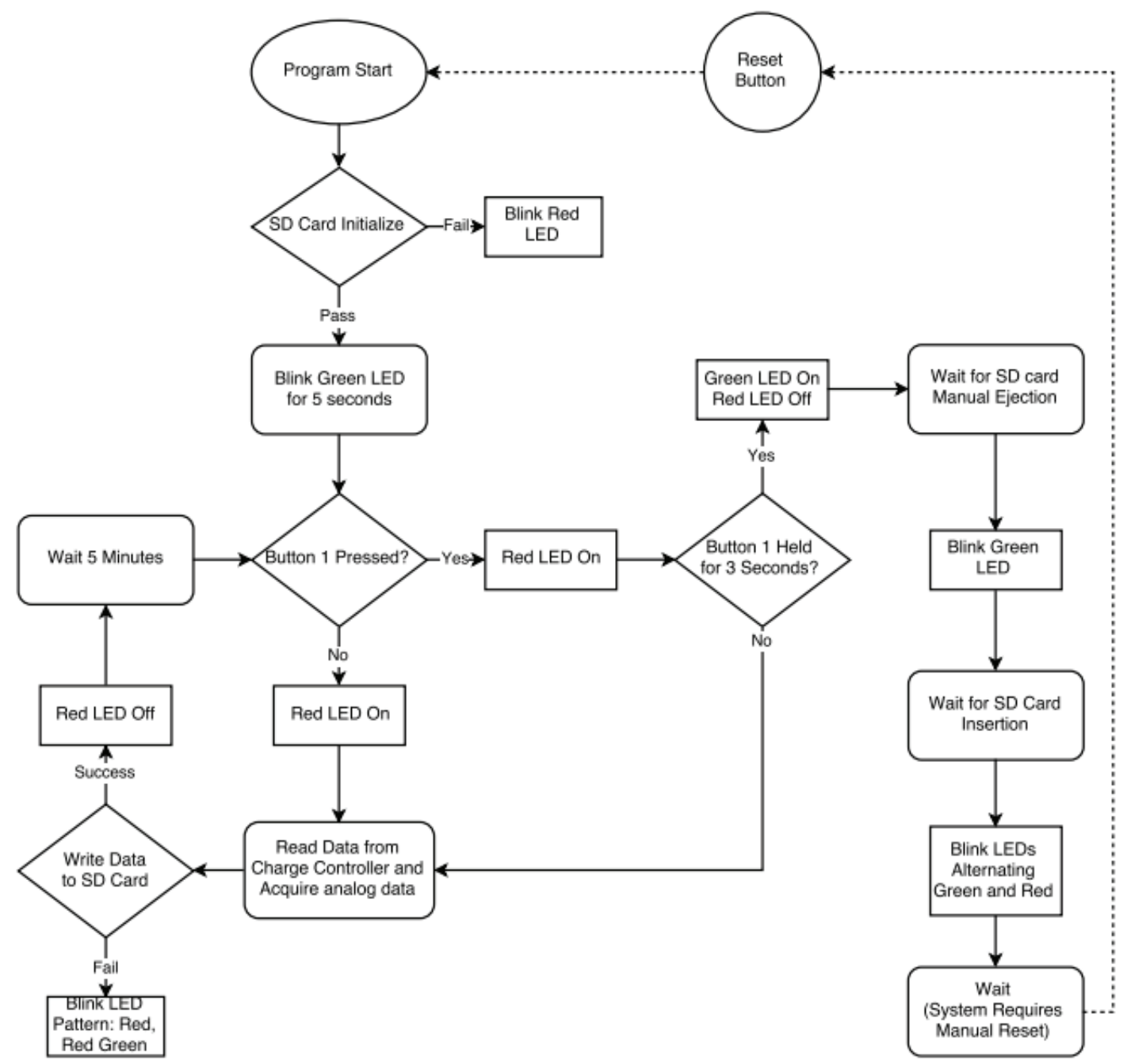

Fig. 5 S4 data logging unit code flowchart.

\section{Implementation}

Two data logging systems were built: the S4 data logger and the wall power data logger. The S4 data logger consisted of a digital board containing the microcontroller, Modbus communication, microSD card reader, the user interface and the communication systems (total cost was \$30.15), and an analog board containing the voltage amplification circuitry for the current sensors (total cost of the board was $\sim \$ 5$ ). The cost of this PV DAS is close to $10 \%$ of the cost of the commercially available systems. The wall power data logger consisted of one circuit board and an AC/DC adapter (total cost was \$46.82). It included a microcontroller, SD card reader, RTC breakout board, a $4.7 \mathrm{mF}$ capacitor across the power input and ground of the microcontroller, the user interface, and power was supplied via an $\mathrm{AC} / \mathrm{DC}$ converter.

\section{Integration and Testing}

\subsection{S4 Data Logging System}

To enable data transfer, an RJ45 cable was used to connect the data logger to the S4. The data written on the microSD card were able to be viewed on a computer to ensure consistency between the recorded data and the data displayed directly on the charge controller. To integrate the analog board, the small sensing resistors were soldered onto copper plates, which were inserted at the ground wire of each of four 
loads. Heat shrink was applied to insulate each current sensing resistor. Due to the variability in resistance in each differential amplifier circuit, calibration plots were acquired. Voltage was measured at each amplifier circuit output while varying the load current from 0 to $2 \mathrm{~A}$ in $0.1 \mathrm{~A}$ steps. Each had a slightly different gain but the relationship between the current and output voltage was linear as expected. Fig. 6 shows the integrated data logging system.

\subsection{Wall Power Data Logging System}

Correct date and time recordings as USB power was removed and reintroduced were ensured. The 4.7 $\mathrm{mF}$ capacitor was able to extend the power sufficiently. Once power was removed the microcontroller, microSD card board, and RTC had power for approximately one second. The time extension of one second was determined to be sufficient for one last recording to the microSD card. The data logger was installed in a location that was not supplied with the same power as the hospital. If diesel is available at the hospital, the hospital is able to be powered via a diesel generator. Thus, if the wall power data logger was to be plugged at the hospital, the data may not have been accurate.

\section{Results}

Since installation, data have been acquired from both data loggers. The errors in the data were minimal at $2.78 \%$. The data were analysed using the MATLAB software. The monitored voltages and currents as a function of time for a typical day in October can be seen in Figs. 7a and 7b, respectively. Fig. 7a illustrates the voltages of the PV panel and the battery. PV panel generates voltage between 5:30 am and 5:30 pm when there is sunlight. The battery voltage increases in the morning when the battery is charging and stays constant throughout the rest of the day. The battery voltage decreases after sunset when it powers the loads, which have the same voltage as the battery. Fig. $7 \mathrm{~b}$ shows the currents of the PV panel and the loads. Consistent with the voltage case, the current of the PV panel increases in the morning when the battery is charged and starts to decrease when the battery voltage reaches the maximum voltage. The load current is sourced by the PV panel during the daytime and by the battery after sunset.

The monitored temperatures of the battery and ambient for a typical day in October are depicted in Fig. 7c. It can be seen that the battery temperature is near the ambient temperature when the battery is not charging nor discharging. Its temperature is greatly increased during both charging and discharging periods.

To determine the usage data, usage was defined as a particular user port being used for more than 15
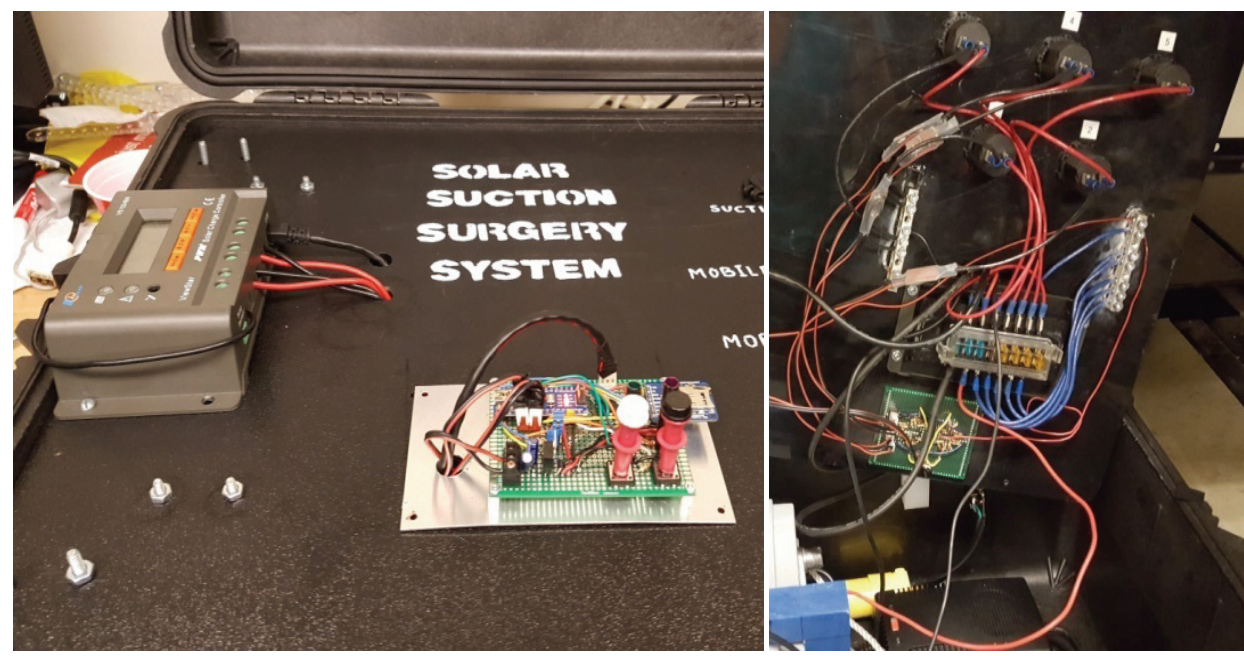

Fig. 6 S4 data logging circuits. 

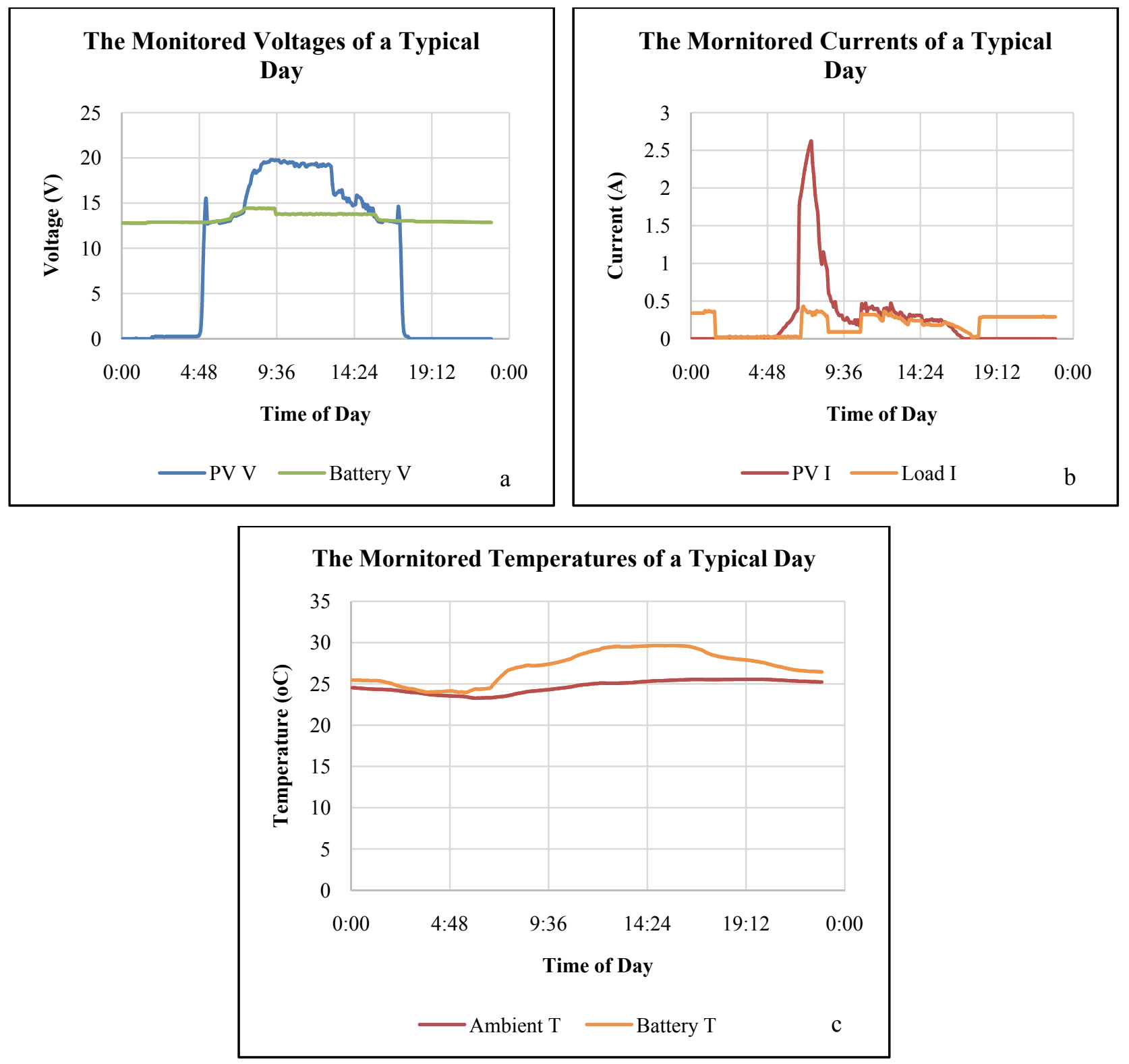

Fig. 7 (a) Monitored voltages, (b) currents, (c) and temperatures, for a typical day.

consecutive minutes at a time, and the current of each port was calculated accordingly. A least-squares linear regression analysis was used to determine the voltage to current conversion coefficients that were used for the determination of the load current of each of the five ports. Fig. 8 shows histograms of the average per day use of each of the four monitored S4 ports and the unit as a whole.

Fig. 8 shows that the S4 is used on Saturdays for longer periods of time than the rest of the week. In addition, out of the monitored ports, the port for charging the suction machine is used most. Overall the usage of the S4 seems to be low, which is expected for the first month of installation as the hospital staff learn to use the equipment.

One and a half months of data was acquired from the wall power data logger. After analysing these data using the MATLAB program, a histogram was generated as seen in Fig. 9, which shows the average number of blackouts lasting between ten minutes and two hours, between two hours and a day, and more than a day. It can be seen from Fig. 9 that there were 


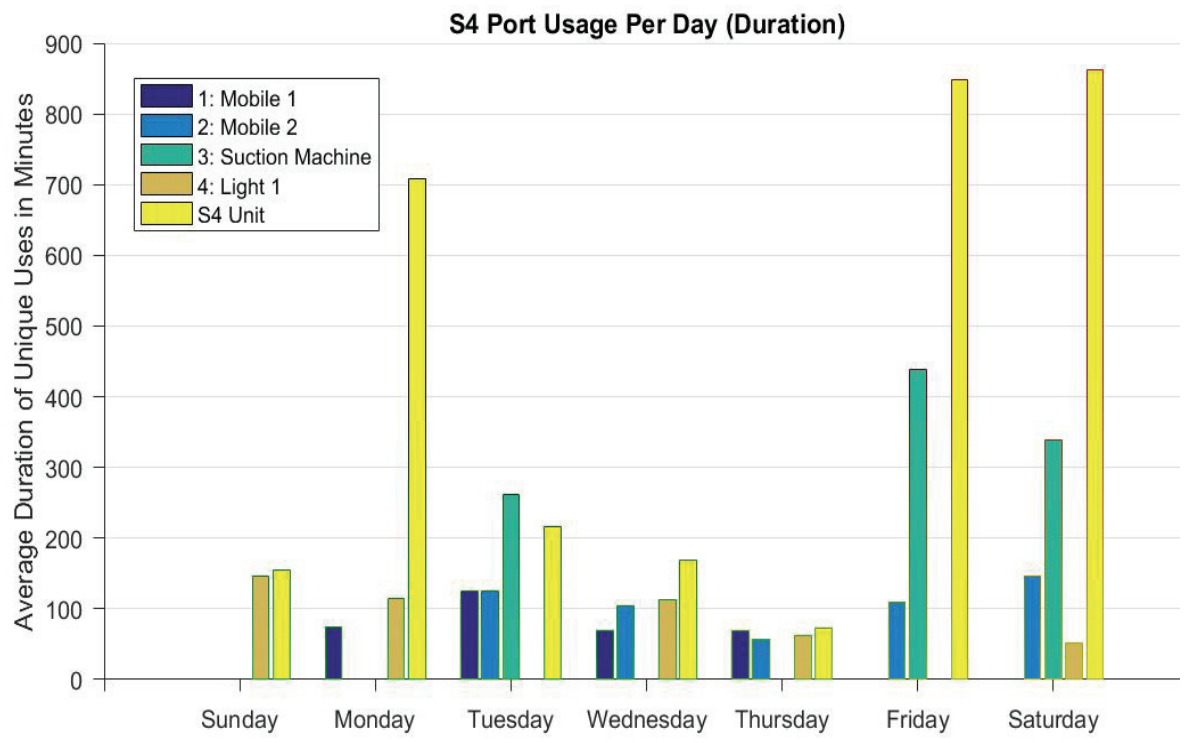

Fig. 8 Average S4 port and S4 unit usage throughout a week.

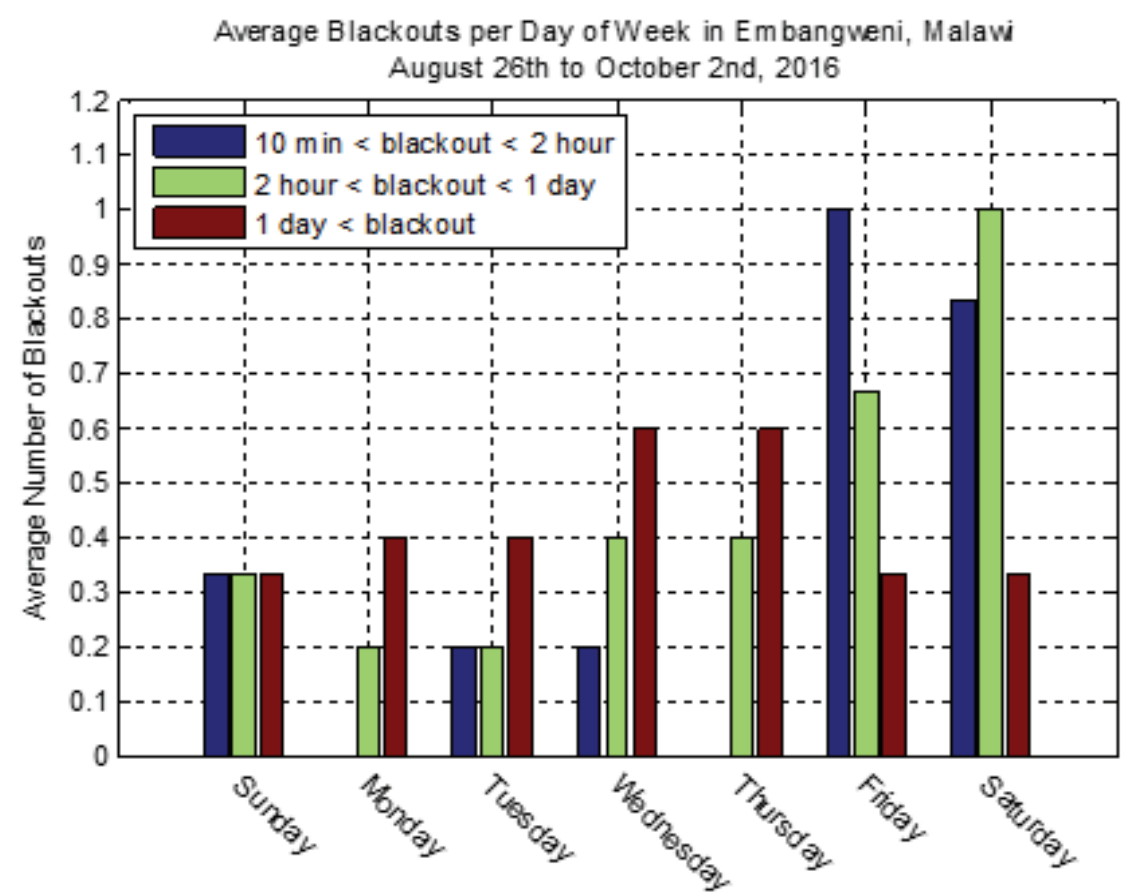

Fig. 9 Average number of blackouts during the week lasting more than 10 minutes, 2 hours, and 1 day.

more frequent short blackouts on Fridays and Saturdays while blackouts on Wednesday's and Thursday's last more than a day. The S4 is used for long periods of time on Fridays and Saturdays which could be due to the need to recharge devices that were used on the previous days when there was no grid power available.
No concrete trends can be established with a month's worth of data. However, it is evident that the acquisition of data using the designed data loggers was successful, and the data loggers have been able to function under real world conditions. The data files are able to be sent via email with ease due to the widespread use of smart phones in Malawi. 
Additionally, the data are able to show the voltage and current changes of the panels and battery throughout the day, usage data of the devices, and power outages of the region. Thus, with additional data analysed, trends may be able to be observed.

\section{Conclusions}

The S4 DAS and the wall power DAS were effective in monitoring the status of PV systems. The two data logging systems provided a means of recording PV system parameters, S4 usage data, as well as power outage data that was low-cost and required little addition of auxiliary sensors. Atmega328 microcontrollers allow for a cost effective and versatile method for acquiring and recording data. The use of SD cards enables low-cost data acquisition of remote systems where availability of computers and installation of servers is not feasible. With increasing usage of the S4 and larger data sets acquired from the data loggers, it may be possible to observe trends. Usage statistics will help improve future system development and possibly establish correlations between the usage of the S4 and regional blackouts in Malawi. Thus far, a baseline can be established for the performance of the system. Once future data sets are analysed, any decrease in overall performance can be observed. Utilizing Atmega328 microcontrollers and readily available breakout boards (e.g. real time clock board, microSD card board) can lower the cost of DASs and allow for increased customization.

\section{References}

[1] Woyte, A., Richter, M., Moser, D., Mau, S., Reich, N., and Jahn, U. 2013. "Monitoring of Photovoltaic Systems: Good Practices and Systematic Analysis." In Proceedings of the 28th European Photovoltaic Solar Energy Conference, Villepinte, 3686-94.

[2] Biswas, L., Rahman, H., and Haque, S. 2012. "A Low Cost Characteristics Analyzer of PV Module.” Presented at the 2nd International Conference on the Developments in Renewable Energy Technology, Dhaka, 1-5.

[3] Mahjoubi, A., Mechlouch, R. F., and Brahim, A. B. 2011.
"A Low Cost Wireless Data Acquisition System for a Remote Photovoltaic (PV) Water Pumping System." Energies 4 (January): 68-89.

[4] Jucá, S. C., Carvalho, P. C., and Brito, F. T. 2011. "A Low Cost Concept for Data Acquisition Systems Applied to Decentralized Renewable Energy Plants." Sensors 11 (1): 743-56.

[5] Mukaro, R., and Carelse, X. 1999. "A Microcontroller-Based Data Acquisition System for Solar Radiation and Environmental Monitoring." IEEE Trans Instrument Measure 48 (6): 1232-8.

[6] Akposionu, K. N., and Nwokoye, A. O. C. 2012. "Design and Fabrication of a Low-Cost Data Logger for Solar Energy Parameters." Journal of Energy Technologies and Policy 2 (6): 12-17.

[7] Fuentes, M., Vivar, M., Burgos, J., Aguilera, J., and Vacas, J. 2014. "Design of an Accurate, Low-Cost Autonomous Data Logger for PV System Monitoring Using Arduino ${ }^{\mathrm{TM}}$ That Complies with IEC Standards." Solar Energy Mater Solar Cells 130 (November): 529-43.

[8] Koutroulis, E., and Kalaitzakis, K. 2003. "Development of an Integrated Data-Acquisition System for Renewable Energy Sources Systems Monitoring." Renew Energy 28 (1): 139-52.

[9] Purwadi, A., Haroen, Y., Ali, F., Heryana, N., Nurafiat, D., and Assegaf, A. 2011. "Prototype Development of a Low Cost Data Logger for PV Based LED Street Lighting System." In Proceedings of International Conference on Electrical Engineering and Informatics, Bandung, 1244-8.

[10] Kalaitzakis, K., Koutroulis, E., and Vlachos, V. 2003. "Development of a Data Acquisition System for Remote Monitoring of Renewable Energy Systems." Measurement 34 (2): 75-83.

[11] Chiandone, M., Cleva, S., Pavan, A., and Sulligoi, G. 2009. "Monitoring Application of Electrical and Climate Data for PV Systems Using Linux RTAI." In Proceedings of International Conference on Clean Electrical Power, Capri, 259-62.

[12] Chowdhury, S., Day, P., Taylor, G. A., Chowdhury, S. P., Markvart, T., and Song, Y. H. 2008. "Supervisory Data Acquisition and Performance Analysis of a PV Array Installation with Data Logger." In Proceedings of the Power and Energy Society General Meeting: Conversion and Delivery of Electrical Energy in the 21st Century, Pittsburgh, 1-8.

[13] Mahzan, N. N., Omar, A. M., Mohammad, S. Z., and Mohd, M. Z. 2013. "Design of Data Logger with Multiple SD Cards." In Proceedings of IEEE Conference on Clean Energy and Technology, Langkawi, 175-80. 